\title{
Nutritional status of underfive children in a pastoral community in Simanjiro District, Tanzania
}

\author{
C.N. M. NYARUHUCHA*, P.S. MAMIRO, A.J. KERENGI \& N.B. SHAYO \\ Department of Food Science \& Technology, Sokoine University of Agriculture, \\ P.O. Box 3006, Morogoro, Tanzania
}

\begin{abstract}
A study was conducted in Simanjiro district in northern Tanzania to determine the nutritional status of underfive children in a pastoral community. Weight and height measurements were carried out on 250 children and that of mean upper arm circumference (MUAC) on 226 children. The z-scores of weight-for-age, weight-for-height and height-for-age indicated that $31.2 \%$ of the children were underweight and $6.0 \%$ were severely underweight. Wasting was observed in $17.2 \%$ children of whom $3.2 \%$ were severely wasted. Severely stunted children were $3.2 \%$ while $14 \%$ were moderately stunted. Measurements of MUAC indicated that $35 \%$ and $3.5 \%$ of the children were moderately and severely undernourished, respectively. The nutritional status of the children under study was slightly lower than the national average. In conclusion, malnutrition in Simanjiro district is prevalent, and therefore, appropriate multidisciplinary approach on nutrition education, environmental sanitation and hygienic practices at family and community level need to be promoted to reduce childhood illnesses thereby increasing child health and nutritional status.
\end{abstract}

Key words: nutrition, children, pastoral community, Tanzania

\section{Introduction}

Nutritional status can be defined as the interpretation of information obtained from the methods of nutritional assessment. The information obtained is used to determine the health status of individuals or population groups as influenced by their intake and utilization of nutrients by the body (Gibson, 1990). The nutritional status is influenced profoundly by diet, infectious and parasitic diseases, and is a major determinant of child's health and survival (Swaminathan, 1989; Joosje et al., 1997). In developing countries, areas that have received attention in the last decade are the survival and healthy development of children especially those under five years of age and the social and economic roles of women (Leslie, 1988; Garcia \& Alderman, 1989). Researchers and planners have tended to view women as an instrument to achieve child health. Ignoring or minimizing the opportunity cost of women's time and the genuine need in most low-income households for mothers to earn income as well as to care for children, is one of the contributing factors to poor nutritional status (TFNC, 1992a).

Malnutrition is increasingly recognized as a prevalent and important health problem in many countries. This problem has serious long-term consequences for the child and adversely influences development of a nation. Most common nutritional problems are Protein Energy Under-nutrition (PEU), iron deficiency anaemia (IDA), iodine deficiency disorders (IDD) and vitamin A deficiency (VAD) (ACC/SCN, 2000). Malnutrition affects adversely the growth and health of children. Undernourished children are therefore expected to attain maturity later

\footnotetext{
* To whom correspondence should be addressed. E-mail: nyaruhu@ suanet.ac.tz
}

than healthy children and even worse, their mental capabilities are very much reduced. Malnutrition certainly creates a huge human and economic waste (URT \& UNICEF, 1990; TFNC, 1992b).

In Tanzania all population groups are affected by malnutrition especially under nutrition. However, children underfive years of age and women, particularly those who are pregnant and lactating are the most vulnerable (Kavishe, 1993). Malnutrition in its severe form still remains a significant cause and determinant of mortality, short-term morbidity, permanently lost productivity and intellectual capacity in societies, which cannot afford such losses and costs (Latham, 1997). One of the most clinical vulnerable age-category is children 4-36 months (UNICEF, 1998). Factors which lead to undernutrition in children, especially underfives have been identified as inadequate food intake due to low feeding frequency during weaning, low energy density of diets and insufficient dietary therapy during and immediately after mild or severe illnesses, that frequently occur (TFNC, 1997a).

Poverty, although not being a direct cause, is one of the most important causes of malnutrition in various parts of the world (Cook et al., 1990; Earl \& Woteki, 1993; Hassan et al., 1997). Poverty limits access to adequate diet, availability of education, health services and healthy environment (Islam, 1997; Beaglehole \& Bonita, 1997). These are essential determinants of good health and satisfactory nutritional status.

Although the causes of nutritional problems and their effects are widely documented (Kavishe, 1993; TFNC, 1997a; Latham, 1997; UNICEF, 1998), their prevalence and influence on nutritional status differ from one area to another. Therefore this study aimed at determining the nutritional status of underfive 
children in a pastoral community subsisting essentially on meat and dairy products.

\section{Material and Methods}

\section{Study area}

The study was conducted in Simanjiro district in northern Tanzania. The area has been earlier described by Nyaruhucha et al. (2005). The study involved children between 6 and 59 months old.

\section{Anthropometric measurements}

The anthropometric variables used in this study were weight, height and mid-upper arm circumference (MUAC). Standard technique and equipment were employed (Gibson, 1990). Weight of a child was measured and recorded to the nearest $0.1 \mathrm{~kg}$ (accuracy of $100 \mathrm{~g}$ ) using Salter scale (Model 235 6S - England) with a capacity of measuring up to $25 \mathrm{~kg}$. The scale was adjusted to read zero before starting the measurements. The Salter scale was hanged on one rafter at the maternal and child health $(\mathrm{MCH})$ clinic. The weight was recorded as soon as the pointer on the scale had stabilized.

Recumbent lengths of the infants were measured using an infant measuring board. The length was measured with the subject lying in a supine position on a length measuring board, which had a fixed head rest and a movable foot piece and placed on a flat surface. Care was taken to maintain the subject's head in an upward upright position, with legs stretched to a full extent and feet at right angles with legs. After positioning the child, the foot piece was moved to touch the feet and the length was recorded to the nearest $0.1 \mathrm{~cm}$. Children with height more than 100 $\mathrm{cm}$ were measured to the nearest $0.1 \mathrm{~cm}$ using a stadiometer (Leicester height measure, CMS weighing equipment, Campden, UK). The measurement was recorded while the subject was standing without shoes on a horizontal flat plate attached to the base of the stadiometer with his/her heels together. The subject was closely observed to ensure that the heels remained on the plate and that the head was in upright position during the measurement. The headpiece was then brought down on the subject's head and reading taken.

Classification of nutritional status basing on standard deviations (SDs) was done according to WHO (1995) cutoff points where $(-3 \mathrm{SD})=$ severe under-nutrition; between $(-3 \mathrm{SD}$ and below $(-2 \mathrm{SD})=$ moderate under-nutrition; between $(-2 \mathrm{SD})=$ and $(+2 \mathrm{SD})=$ normal nutritional status and above $(+2 \mathrm{SD})=$ over-nutrition.

MUAC was measured by using Talc insertion tape (Talc Ltd, St. Albans, UK). The child's arm was uncovered as far as the shoulder, and the arm was bent and the lower arm placed across the stomach while the child was looking straight ahead. The tip of the bones at the elbow and top of the shoulder was located and the distance between the two marked tips was measured and divided by two, to get midway point.

Then the child's arm was hung at the sides. The tape was placed around the arm at the marked midway point, and care was taken to make sure that the tape fitted comfortably around the arm (i.e. not too tight or too loose). Measurements were taken to the nearest $0.1 \mathrm{~cm}$ MUACs were calculated and used to assess children nutritional status. In this study MUAC was measured among children aged 6-59 months, because below this age it will overestimate or underestimate the nutritional status of a child (Arbelot, 1995; WHO, 1995). Children were classified according to their nutritional status according to Gibson (1990). Age was obtained from the neonatal cards.

\section{Data analysis}

Anthropometric data (z- score) were entered and analyzed using Epi lnfo 6.04d (CDC, Atlanta Georgia, USA). Anthropometric indicators used were heightfor-age, weight-for-age, and weight-for-height and these were compared to reference values recommended by National Centre for Health Statistic (NCHS) (WHO, 1995). Data from questionnaire were coded and analysed using the Statistical Package for Social Sciences (SPSS) (Norusis/SPSS Inc, 1995) version 9.0 for Windows.

Table 1: Number (\%) of children with weight-for-age z-score (waz) in Simanjiro

\begin{tabular}{|c|c|c|c|c|c|}
\hline $\begin{array}{l}\text { Age } \\
\text { group (months) }\end{array}$ & $(-2 S D)-(+2 S D)$ & $<(-2 S D)-(3 S D)$ & $<(3 S D)$ & $>(+22 S D)$ & Total \\
\hline $0-11$ & $58(23.2)$ & $8(3.2)$ & $0(0)$ & 0 & $66(26.4)$ \\
\hline $12-17$ & $27(10.8)$ & $13(5.2)$ & $1(0.4)$ & 0 & $41(16.4)$ \\
\hline $18-23$ & $17(6.8)$ & $7(2.8)$ & $1(0.4)$ & 0 & $25(10.0)$ \\
\hline $24-35$ & $30(12.0)$ & $18(7.2)$ & $7(2.8)$ & 0 & $55(22.0)$ \\
\hline $36-47$ & $25(10.0)$ & $7(2.8)$ & $6(2.4)$ & 0 & $38(15.2)$ \\
\hline $48-59$ & $15(6.0)$ & $10(4.0)$ & $0(0)$ & 0 & $25(10.0)$ \\
\hline Total & $172(68.8)$ & $63(25.2)$ & $15(6.0)$ & 0 & $50(100)$ \\
\hline
\end{tabular}




\section{Results}

The results show that, $68.8 \%$ of children had normal nutritional status, $25.2 \%$ were moderately undernourished and $6.0 \%$ were severely undernourished while no one was overweight (Table 1).
Eighty-two per cent of the children had normal nutritional status while $0.8 \%$ were overweight for their heights, $14.0 \%$ were moderately wasted and $3.2 \%$ were severely wasted (Table 3 ).

The rate of malnutrition according to age group shows that there is a statistical significant difference

Table 2: Number of children (\%) with height-for-age z-score (haz) in Simanjiro

\begin{tabular}{lccccc}
\hline $\begin{array}{l}\text { Age } \\
\text { group (months) }\end{array}$ & $\mathbf{( - 2 S D ) - ( + 2 S D )}$ & $<(-\mathbf{2 S D})-(-\mathbf{3 S D})$ & $<(-3 S D)$ & $>(+\mathbf{2 S D})$ & Total \\
\hline $0-11$ & $54(21.6)$ & $9(3.60)$ & $2(0.8)$ & $1(0.4)$ & $66(26.4)$ \\
$12-17$ & $20(8.0)$ & $10(4.0)$ & $1(0.4)$ & $10(4.0)$ & $41(16.4)$ \\
$18-23$ & $18(7.2)$ & $4(1.6)$ & $2(0.8)$ & $1(0.4)$ & $25(10.0)$ \\
$24-35$ & $41(16.4)$ & $8(3.2)$ & $2(0.8)$ & $4(1.6)$ & $55(22.0)$ \\
$36-47$ & $27(10.8)$ & $6(2.4)$ & $1(0.4)$ & $4(1.6)$ & $38(15.2)$ \\
$48-59$ & $17(6.8)$ & $5(2.0)$ & $1(0.4)$ & $2(0.8)$ & $25(10.0)$ \\
Total & $177(70.8)$ & $42(16.8)$ & $9(3.6)$ & $22(8.8)$ & $250(100)$ \\
\hline
\end{tabular}

Of the children examined, $76.8 \%$ had normal nutritional status, $82 \%$ were moderately stunted, $3.6 \%$ were severely stunted (Table 2).
$(P<0.05)$ between one age group and the other. Children with the age between 24-35 months had high rate of malnutrition followed by those aged 36-47

Table 3: Number (\%) of children with weight-for-height z-score (whz) in Simanjiro

\begin{tabular}{|c|c|c|c|c|c|}
\hline $\begin{array}{l}\text { Age } \\
\text { group (months) }\end{array}$ & (-2SD)-(+2SD) & $<(-2 S D)-(3 S D)$ & $<(3 S D)$ & $>(+2 S D)$ & Total \\
\hline $0-11$ & $59(23.6)$ & $5(2.0)$ & $1(0.4)$ & $1(0.4)$ & $66(26.4)$ \\
\hline $12-17$ & $30(12.0)$ & $9(3.6)$ & $1(0.4)$ & $1(0.4)$ & $41(16.4)$ \\
\hline $18-23$ & $18(7.2)$ & $6(2.4)$ & $1(0.4)$ & 0 & $25(10)$. \\
\hline $24-35$ & 48 (19.2) & $5(2.0)$ & $2(0.8)$ & 0 & $55(22.0)$ \\
\hline $36-47$ & $30(12.0)$ & $6(2.4)$ & $2(0.8)$ & 0 & $38(15.2)$ \\
\hline $48-59$ & $20(8.0)$ & $4(1.6)$ & $1(0.4)$ & 0 & $25(10.0)$ \\
\hline Total & 205 (82.0) & $35(14.0)$ & $8(3.2)$ & $2(0.8)$ & 250 (100) \\
\hline
\end{tabular}

Table 4: Nutritional status by sex of a child based on MUAC in Simanjiro

\begin{tabular}{lccc}
\hline State of nutrition & Male & Female & Total \\
\hline Normal & $69(30.5)$ & $70(31.0)$ & $139(61.5)$ \\
Moderate & $36(15.9)$ & $43(19.0)$ & $79(35.0)$ \\
Severe & $2(0.9)$ & $6(2.7)$ & $8(3.5)$ \\
Total & $107(47.3)$ & $119(52.7)$ & $226(100)$ \\
\hline
\end{tabular}

Results showed that $61.5 \%$ of children had normal nutritional status, $35.0 \%$ were moderately undernourished and $3.2 \%$ were severely undernourished (Table 3 ). When children were grouped according to sex it was found that $30.5 \%$ of males and $31.0 \%$ females had normal nutritional status, $15.9 \%$ males and $19.0 \%$ females were moderately undernourished, whereby $0.9 \%$ males and $2.7 \%$ females were severely undernourished (Table 4). months. There was no significant difference $(P>0.05)$ between nutritional status and sex of the child.

\section{Discussion}

In this study the severe forms of malnutrition depicted by low waz, haz and whz, were common in the first and second year of life and continued to the third year. It is possible that in infancy due to universal breast-feeding 
habit, children grow normally up to the age of 6 months, thereafter inadequate breast-feeding, improper complementary foods and the high rate of infection result in growth retardation and subsequent increase in the prevalence of malnutrition (Mamiro et al., 2004). Children with the age of 24-35 months are highly affected because they are in the active growth stage and if their diet is inadequate to meet their physiological needs they end up being malnourished (WHO, 1999). Other workers in Tanzania (TFNC, 1997a, b; TDHS, 2000) have also observed a similar trend in children of 3 years old. It can be noted that the critical period of growth retardation coincides with the weaning period implying that there is inadequacy either in quantity or quality of complementary foods. Frequent illnesses such as malaria, diarrhoea, respiratory infections and worms are likely to exacerbate the problem of undernutrition in such children. Nutritional status of children observed in this study indicates that prevalence of undernutrition is high in this district.

Underweight (low weight-for-age) is an indicator of either acute or chronic under-nutrition. Total underweight (severe + moderate) in our study is high compared with the regional average of $28.5 \%$ (URT, 1998) and that reported by Tanzania Demographic and Health Surveys (TDHS, 2000) (29-31\%). From these results it implies that the problem of undernutrition is still high in Tanzania. In this study children between 011 months showed no prevalence of severe underweight. This is probably due to the fact that it is the age group in which mother's breast milk is supplemented with complementary foods to meet the child's increased demand. According to Kreutler (1980), low weight-forage at the age of $0-11$ months is due to stunting rather than wasting. The low prevalence of weight-for-age in age group 48-59 months is likely to be due to the fact that children at this age group are old enough to eat a variety of foods including normal family meals. Children between 24-35 months show the highest prevalence of low weight-for-age than relatively younger children due to increased activity and high physiological need of nutrients by this age group.

Also this is the age group that is more susceptible to illnesses such as malaria, diarrhoea, respiratory infections and worms (Stoltzfus et al., 1997). Poor quality complementary foods may result into a deficit tissue and fat mass compared particularly after illness. Therefore, adequate breast-feeding, combined with timely and proper complementary feeding are important in ensuring child health and normal growth (Kirsten et al., 2001).

The height-for-age reflects achieved linear growth. Low height-for-age indicates a child whose height-for-age is below minus two standard deviation $(-2 \mathrm{SD})$ from the median of the reference population. Highest percentage of stunting was observed among infants than relatively older children. Apart from other physical and physiological dimensions, stunting usually results from prolonged inadequate intake of food as well as diseases making infants to have a low height for their age (Lartey et al., 1999). This observation suggests that nutritional problems start at very early age. This pattern highlights that the first two years of life is the most nutritionally vulnerable period for children in the study area. Therefore appropriate nutritional efforts need to be focused at much earlier age.

Wasting is a measure which indicates low weightfor-height below -2SD. The results of our study show that percentage wasted is higher than that observed by Tanzania Demographic and Health Surveys, which was $7 \%$ moderately wasted and $1 \%$ severely wasted (TDHS, 1997). Wasting indicates deficit in tissue and fat mass compared with amount expected in a child of the same height or length and may result either from failure to gain weight or from actual weight loss. Most of children in this study $(50.8 \%)$ were fed only three times per day. This high percentage of wasting observed might have been due to failure to receive adequate nutrition or recent episodes of illness causing loss of weight.

In conclusion, the results of this study indicate that malnutrition in Simanjiro district is a problem among children. Appropriate multidisciplinary approach on nutrition education, environmental sanitation and hygienic practices need to be promoted at family and community levels to improve nutrition of the children and reduce childhood illnesses.

\section{References}

ACC/SCN (2000) Fourth Report on the World Nutrition Situation. United Nations; Geneva. Pp 20-34.

Arbelot, A.M. (1995) Guideline for Assessing the Nutritional Impact of Supplementary Feeding Programmes for Vulnerable Groups. San Frontires, Paris. Pp 2-6.

Beaglehole, R. \& Bonita, R. (1997) Public Health Cross Road Achievement and Prospects. Cambridge University Press; London. Pp 2025-2070.

Cook, J.D., Skikine, B.S. \& Baynes, R.D. (1990) Screening strategies for nutritional Iron Deficiency. Proceeding of $30^{\text {th }}$ Nestle Workshop on Nutrition Anaemia, 3-5 June 1990, Toronto, Pp 12-34.

Earl, R. \& Woteki, C.E. (1993) Iron Deficiency Anaemia Recommended Guidelines for the Prevention, Detection and Management Among us. Children and Women of Child Bearing Age, National Academy Press; Washington DC. Pp 420-440.

Garcia, M. \& Alderman, H. (1989) Patterns and determinants of malnutrition in children in Pakistan: impact of community health. 
Pakistan Development Review 28, 891-902.

Gibson, R.S. (1990) Principles of Nutritional Assessment. Oxford University Press New York. Pp 3-10.

Hassan, K., Sullivan, K.M., Yip, R. \& Woodruff, B.A. (1997) Factors associated with anaemia in refugees children. American Journal of Clinical Nutrition. 127, 2194-2198.

Islam, R. (1997) Poverty and its Effect on Nutrition Some Questions Based on Asian Experience. ACC/SCN Symposium March 17-21 1997, Kathmandu; Nepal. Pp 17-32

Joosje, P. L., Langenhoven, M.L., Kriek, J.A., Kunenke, E. \& Nyaphisi, M. (1997) Nutritional status of rural children in Lesotho. East African Medical Journal 74, 132-164

Kavishe, F. P. (1993) Nutrition Relevant Actions in Tanzania. Tanzania Food and Nutrition Centre, 20 ${ }^{\text {th }}$ Anniversary 1973-1993. Monograph Series No. 1. UN-ACC/SCN Country Case Study. A case study for the XV Congress of the International Union of the Nutrition Sciences, September 26 to October 1, 1993, Adelaide, Pp180-230.

Kirsten, B.S., Simondon, F., Costes, R., Delaunay, V. \& Diallo, A. (2001) Breastfeeding is associated with improved growth in length, but not weight, in rural Senegalese toddlers. American Journal of Clinical Nutrition 73, 959-967.

Kreutler, P. (1980) Nutrition in Perspective. Prentice Hall Inc Englewood Cliffs: New Jersey. Pp 500-504.

Lartey, A., Manu, A., Brown, K.H., Peerson, J.M. \& Dewey, K.G. (1999) A randomized, community-based trial of the effects of improved, centrally processed complementary foods on growth and micronutrient status of Ghanian infants from 6-12 months of age. American Journal of Clinical Nutrition 70, 391-404.

Latham, M.C. (1997) Human Nutrition in the Developing World. Food and Agricultural Organization of United Nations, Rome. Pp 20-120.

Leslie, J. (1988) Women's work and child nutrition in the third world. World Development Journal 16, 1341-1362.

Mamiro, P., Kolsteren, P., van Camp, J., Roberfroid, D., Tatala, S. \& Opsomer, A. (2004) Processed complementary food does not improve growth or hemoglobin status of rural Tanzanian infants from 6 to 12 months of age in Kilosa District, Tanzania. Journal of Nutrition 134, 1084-1090.

Nyaruhucha, C.N., Mamiro, P.S. \& Kerengi, A.J. (2005) Prevalence of anaemia and parasitic infections among underfive children in
Simanjiro District, Tanzania. Tanzania Health Research Bulletin 7, 35-39.

Stoltzfus, R.J., Chwaya, H.M., Albonico, M., Schulze, K.J., Savioli, L. \& Tielsch, J.M. (1997) Serum ferritin, erythrocyte protoporphyrin and haemoglobin are valid indicators of iron status of school children in a malaria-holoendemic population. Journal of Nutrition 127, 293298.

Swaminathan, M. (1989) Principles of Nutrition and Dietetics. The Bangalore Press, Bangalore, Pp 40-56.

TDHS (1997) Tanzania Demographic and Health Surveys, Dar-es-salaam. Calverton MD, Planning commission/ Macro International Inc. p 312.

TDHS (2000) Tanzania Demographic and Health Surveys, Dar-es-salaam. Calverton MD, Planning commission/ Macro International Inc. p 226.

TFNC (1992a) An Evaluation of the Tanzania Food and Nutrition Report No 1180. Dar es Salaam, Tanzania. Pp 14- 40

TFNC (1992b) The Food and Nutrition Policy for Tanzania. Tanzania Food and Nutrition Centre Dar es Salaam; Tanzania. Pp 1-32.

TFNC (1997a) Nutritional Status Among Children Aged 6-59 Months in Nzivi Village Kisarawe. Tanzania Food and Nutrition Centre, TFNC report No. 1817. Dar es salaam; Tanzania. Pp 7-45.

TFNC (1997b) Rapid Assessment of Household Food Security and Nutrition in Drought Affected Areas in Tanzania Mainland. Tanzania Food and Nutrition Centre, TFNC report No. 1386. Dar-es-Salaam, Tanzania. Pp 2-19.

UNICEF (1998) The State of the World Children. United Nations Children's Fund, Oxford University Press: New York. Pp 9-98.

URT (1998) Arusha Socio-Economic Profile. Joint publication by the planning commission and regional commissioner's office Arusha Tanzania; United Republic of Tanzania, p 292.

URT \& UNICEF (1990) The Situational Analysis of Women and Children in Tanzania Dar es salaam Tanzania. United Republic of Tanzania and United Nations Children's Fund. Pp140-154.

WHO (1995) Physical Status, the Use and Interpretation of Anthropometry. World Health Organization Expert Committee. Technical Report Series No 854.Geneva; Switzerland. p 125.

WHO (1999) Complementary feeding of young children in Africa and the Middle East. World Health Organization, Geneva, p 426. 